\title{
Review of Electricity Markets for Smart Nano-Grids
}

INGENIERIA ELECTRICA

\section{Mercados Eléctricos para Nano-Redes Inteligentes}

\author{
Willyam M. Viñán ${ }^{1 \S}$, Edwin M. García ${ }^{1}$ \\ Universidad Politécnica Salesiana. Departamento de Posgrados Quito, Ecuador ${ }^{1}$

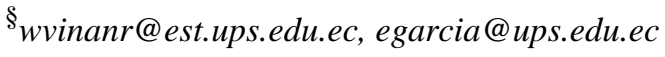

(Recibido: 31 de Enero de 2019 - Aceptado: 21 de junio de 2019)

\begin{abstract}
This article is focused in reviewing the electricity markets models and the smart nano-grids characteristics, making a study about the main aspects related, structure and integration. Previous investigations are discussed and fundamental ideas are developed and explained, and finally variables and constraints are exposed for modelling the electricity market including the considerations for smart nano grids.
\end{abstract}

Keywords: Demand response, Electricity market, Hierarchical energy resources, Smart grid.

\section{Resumen}

Este artículo se enfoca en revisar los modelos de mercados eléctricos y las características de las nano redes inteligentes, realizando un estudio de los aspectos principales, estructura e integración. Investigaciones previas son discutidas e ideas fundamentales son desarrolladas y explicadas, y finalmente variables y restricciones son expuestas para modelar un mercado eléctrico incluyendo las consideraciones para nano redes inteligentes.

Palabras Clave: Respuesta de la demanda, Mercado eléctrico, Recursos energéticos jerárquicos, Red inteligente. 


\section{Introduction}

Hierarchical energy resources are the ideal purpose to follow and to solve a variety of problems related with electricity scarcity, environmental problems and a sustainable society in terms of energy ${ }^{(1)}$. Consequently this theory calls for a prioritization of the concepts to improve the sustainability of the energy system being the most important aspect energy saving, followed by energy efficiency, renewable energy production, and low and high environmental impact energies as shown in

\section{Figure 1.}

The smart grid concept involves a variety of aspects of the electric system including demand response, electricity markets, distributed generation (2), energy storage (3), DC control lines, peak-shaving technologies and even the application of the principles of the hierarchical energy resources; also it refers to the emerging field of electric vehicles and other electricity powered devices with their consequent projected increased demand of large amount of electric energy. More benefits could be taken out from the application of smart grids such as fairer costs of electricity during peak hours ${ }^{(4)}$ which without a smart grid have to be averaged out and passed on equally to all consumers, and in the case of smart grid existence every person pays for their own usage with differential tariffs.

To meet the actual requirements of the smart grid capabilities it is necessary to make a redesign and to deploy technology all around the whole electricity system and mainly on distribution and commercialization branches ${ }^{(5)}$, this involves the necessity of communication and control which allows the consumers manage their load and get economic incentives for them at the same time that the electric sector and the environment get their own benefits.

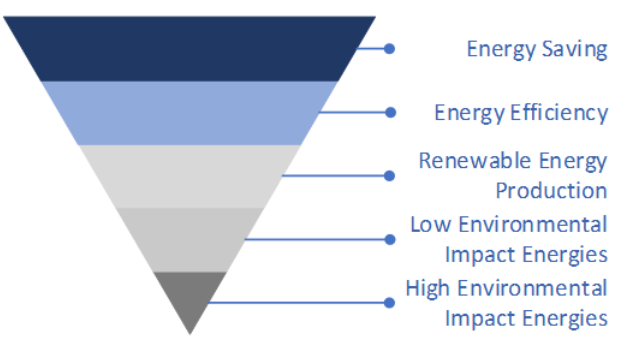

Figure 1. Hierarchical Energy Resources

Various load, energy and metering controllers have been studied and proposed, which are a key tool for consumers to get a more active participation (6) and provide a better demand response; consequently constituting themselves a fundamental part of the hierarchical energy resources as intended.

The connection of a smart nano-grid to the existing power grid must be done in such a way that it doesn't affect the existing power grid in terms of reliability and stability; for this reason appropriate technology such as the mentioned in (2), considerations and cautions must be implemented to achieve the known improvements smart nano-grid offers without the counter back of affecting the existing grid.

An important part of Demand Side Management (DSM) is Demand Response (DR) which deals with the consumers' behavior and how it can be modified to achieve different objectives. This provides a tool to get a more active participation of customers into the energy market bringing multiple benefits for the participants, as for example reduction in users' payments for electricity, optimization of the investments made by electric distribution, transmission and generation owners, benefits for the environment by increasing the use of sustainable sources of energy, in summary approaching the electricity system to the theory of hierarchical energy resources ${ }^{(7)}$. 
Electricity pricing and economic incentives are the primary mechanisms used for achieving consumers participation and consequently shaping the demand curve in the way necessities require ${ }^{(8)}$, which in general points for flattening the daily demand curve. Time of Use (TOU) and Real Time Pricing (RTP) tariffs are pricing systems applied in many different schemes of electricity markets; in the case of TOU cheaper tariffs are stablished for the group of hours in which demand is low and generation can easily handle it, conversely higher rates are charged for those hours of peak electricity usage, obtaining with this, a control over demand and the possibility of lowering the bills for the consumers, as benefits. The differential tariffs of TOU are established in advance and change usually on a seasonal basis.

Meanwhile, RTP has a more volatile pricing scheme than TOU, because in this case tariffs vary hour-to-hour depending on the wholesale market prices and for this reason consumers need to be constantly informed about the price of electricity at any given moment through the use of smart meters and internet for communication.

From the point of view of interaction with the electric grid and according to the properties explained for the smart grid and traditional grid, in few words it could be said that traditional grid is a rigid system and in contrast smart grid is a flexible system ${ }^{(9)}$; this is because of the level of interaction participants of the electricity market can have in relation with the electric grid and the way they can shape many aspects of the electric market with the help of the new technology employed in smart grids.

\section{Electricity Markets}

\subsection{Electricity Markets Main Structure}

It can be found various models of electricity supply industry over the years and along the different territories, as for example the case of monopoly in which one company owns generation, transmission and sometimes even distribution and retail selling.

There are also more flexible models that break in part the monopoly and allow that different companies to take charge of generation and distribution-retailing at least in part of the total demand, but the monopoly still exists with regard to the wholesale trading agency in charge of buying electricity from generators, transmitting it and selling it to distributors. It is necessary to exist a clear regulation for this wholesale trading agency being it a monopoly for the distributors and a monopsony for the generators ${ }^{(10)}$.

The previous model explained can be modified with regard to the wholesale trading agency which is divided and now the transmission system is the only part in the wholesale market that is under the charge of a monopoly. On the other hand, transactions between generators and distributors are made directly in the wholesale market.

One more aspect can be liberalized from this model and it is the retail market, consequently customers can choose the retailer to buy electricity from. Distribution network is common for all retailers in the same way transmission system is, therefore it also must be adequately regulated because it is a monopoly.

Transmission and distribution networks are in theory considered a monopoly, however it is questionable because not all those networks must be owned by the same company, but instead for example expansions to serve unattended demand (11) can be built and administrated by another company.

There are pros and cons between introducing competition and having a monopoly in the electricity supply industry, as for example the advantages of the monopoly are the possibility of coordinating maintenances, working for a global 
least cost operation of the system, meeting technical capacities of transmission, generation and distribution. These mentioned facts can be achieved by the competitive electricity markets but it requires in theory a bigger effort.

On support of competition side, it can be said that profit is a real motivation for efficiency, good service, availability and better studied and thought investments by which the risk is assumed by the investors and not passed to the consumers (12). All of these advantages of competition are totally dependent and relative to the adequate regulation established for the electricity supply industry (Figure 2).

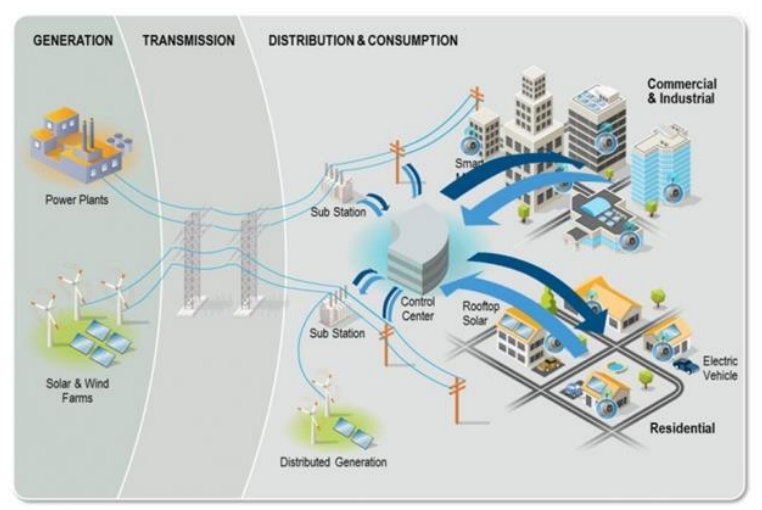

Figure 2. Electricity System Technical Diagram

\subsection{Electricity Markets Characteristics}

Referring to electricity markets, an introductory analysis must be made assuming all generators and loads are connected to a lossless network, consequently the additional variables introduced by transmission and distribution will be ignored and the focus will be on the trading of electrical energy.

Electricity markets have the particularity of maintaining the balance between supply and demand at every moment, no mattering the cost for this, because an unbalance can produce a partial or total collapse of the system bringing very negative economic and social consequences whose magnitude no government could allow.

Another difference electricity markets have with regard to other markets is that energy produced by a specific generator cannot be directed to a determined consumer because power is pooled in the transmission and distribution systems associated before being routed to the loads ${ }^{(13)}$. As consequence a failure in this type of system does not only affect to the parties involved in a transaction but all participants.

Buyers, in this case large consumers and retailers must predict the amount of energy they are going to require for every market period, on the other hand generators who are the sellers schedule their energy production to meet with the terms they have established for the sale. It is technical impossible to both parties, buyers and sellers, to satisfy perfectly the contractual conditions stipulated, in case of buyers their predictions are not exactly the same as the users demand at every period, and in case of sellers their schedules can be affected by any unexpected technical issue.

These inconvenients produce gaps between supply and demand that have to be solved instantly to maintain reliability and prevent from electrical failures, the solution is technically impossible to be given by the free open market, then a managed spot market comes into place which match residual load and generation at every time when the electricity system is in normal conditions and also when it is in a contingency state.

Markets can be classified in two main groups: bilateral trading and electricity pools, which are opposed in conception, implementation and results.

Electricity markets allow for bilateral trading between a buyer and a seller including a contract 
and no interference from a third party, these contracts differ in the amount of energy and lapse of time established.

Another mechanism of market is the electricity pool which is less sophisticated than the previous case and it is easier to apply, beginning with the bids proposed by generators specifying in them the amount of energy with a specific price for the lapse of time treated, then these bids are ranked from the cheapest to the most expensive.

On the other hand, consumers present offers with the amount of energy at a specific price they require for the same period under consideration, then they are ranked in a decreasing manner. Due to inelasticity of electricity demand in some cases this procedure is replaced by a load forecast.

The next step is to accept the bids proposed by generators starting from the cheapest one until demand is satisfied, this point is economically known as the market clearing price, which consists in the price of one additional megawatthour of energy after this point, and it is also called as the system marginal price. This is the price generators receive for every megawatt-hour they deliver to the load and this is the price consumers pays for every megawatt-hour they utilize, no mattering the bids and offers they have submitted.

Pool and bilateral models have each one their particularities that become strengths and weaknesses, as for example the scheduling risk with their consequent start-up and no-load prices that generators face which is a problem when market is totally free and causes an increase in prices proposed by generators. To both cases some rules including complex bids from generators can be incorporated including marginal, start-up and no-load costs; however as always and increase in rules and complexity can result in a loss of price transparency ${ }^{(14)}$.
An arguable point of pool models is that direct negotiations between producers and consumers are not carried on and thus efficient prices cannot be reached. Finally, for any model under consideration it is absolutely important to keep in mind the incentives for electricity consumers and in the wide aspect the hierarchical energy resources considerations.

To complement any of the market chosen before, it is necessary to balance generation and consumption, and in case of electricity this balance has to be made on the time it happens and a conventional spot market is not adequate, then a system operator is summoned into the business who is in charge of maintaining the system balance making use of a managed spot market. Bids and offers are accepted by the system operator and no bilateral deals are performed.

Competition is stablished among parties who want to participate adjusting production or consumption; generators can bid to increase their production or can offer to pay to reduce it too, on the side of consumers they can offer to reduce their consumption or even can offer to increase it, as a result the system operator is able to choose the best options and get the minimum price to achieve the balance ${ }^{(15)}$.

Long term basis contracts can be used in case they represent a better option than short term ones, in these cases generation companies are paid for maintaining available an established generation capacity and also are paid a different value for each megawatt-hour they are required to produce when the system operator decide.

Not every megawatt-hour has the same cost, there are some megawatt-hours crucial to prevent the system from collapsing and in theory they are the most expensive. Bids must specify also the quickness of execution for the system operator to decide for them. 
System operator needs time to execute balance and for this it is necessary that energy trading stop at a certain amount of time before real time. The greater this lapse of time the better for the system operator because it has more time to select and plan what resources will be used. On the other hand, participants of the electricity market prefer shorter intervals because uncertainty and risk are reduced ${ }^{(16)}$.

In case of bilateral trading the system operator is officially informed with the bids and offers of producers and consumers, this information is contrasted with the load forecast and then the probable imbalance is calculated and system operator anticipate which balancing mechanisms will use from the managed spot market. In case of electricity pools natural market and managed spot market are so close that a distinction can hardly be established.

In order to sold energy in the managed spot market, generators have to be flexible in their output to achieve the adjustment the system needs at a specific time, contrary to the bulk generation which is provided by machines in which it is not necessary for them to have a rapid response.

There are other services like voltage, frequency and load following that have to be served in the electricity system and generators can enter into this business too. To perform these services relatively small amounts of energy are required that are charged in a different manner than the regular service.

A centralized settlement system is required to economically balance the discrepancies between the amounts of energy specified in contracts and energy that actually was produced or consumed depending the case. In case of generators if one of them has produced more energy than the energy contracted it is considered that it has sell it to the system, conversely if it has produced less than contracted it is considered that it has bought from the system. In case of consumers, if one of them has consumed more energy than the amount contracted, it is considered to have bought the rest of energy from the system, and in the opposite case it is considered to have sold energy to the system ${ }^{(17)}$. The price used for these transactions is the spot market price. The situation explained happens just for bilateral markets, because pool markets have a different business scheme and this situation is not present (iError! No se encuentra el origen de la referencia.).

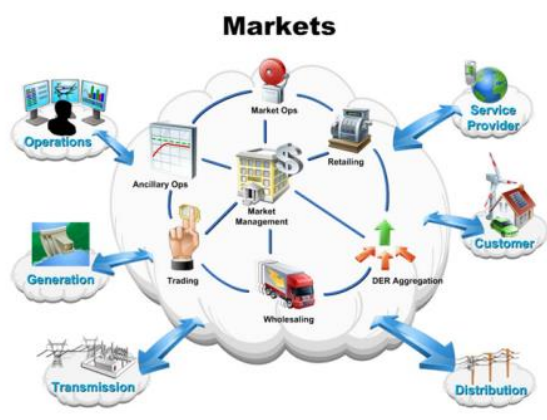

Figure 3. Electricity Market Composition

\section{Electricity Market Modelling Applied for Smart Nano-Grids}

Electricity market is a key part of achieving an active participation of energy consumers, however the mentioned market is not a common one but it has their special particularities and constraints due to its lack of storage capacity, continuous variations of supply and demand, load congestion dispatch, or consumers waiting for the service, all of this in optimal operation (18).

For a correct modelling of an electricity market it is necessary to keep in mind the precepts related to smart grids, hierarchical energy resources, demand response and their respective correlations with ancillary topics in order to address an applicable and realistic model that covers the main aspects and focus on the specific 
intentions of its respective investigation, achieving therefore the sustainability in all aspects of the model proposed overtime (iError!

\section{No se encuentra el origen de la referencia.).}

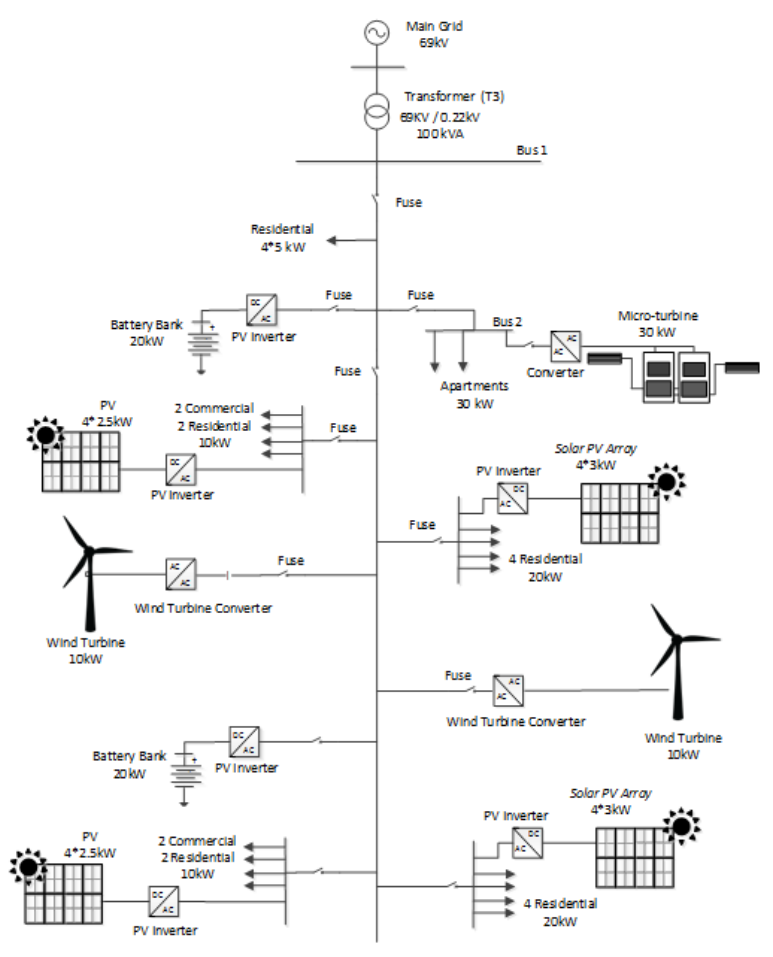

Figure 4 Electricity Smart Grid Integration

To establish an electricity market model it is necessary to define the purpose of the model, the interrelation between the economic and technical aspects, applicability to generation and/or transmission and/or distribution, in other words to the wholesale electricity market or retail electricity market or even a mixture or special case ${ }^{(19)}$; all of this depending on the technology to date available that continuously modifies the electricity market structure.

Features of smart nano-grids like energy storage through the use of batteries, distributed generation such as solar, wind or combine heat and power generators, smart metering and devices, have to be taken into account for modelling the respective electricity market since they include some additional variables, constraints, rules and economic trades. A consequence of this is that roles of some participants of the electricity market are changed as for example in case of consumers who can then even sell energy to the grid, this situation also applies for the possible new energy traders who can settle in the distribution branches.

An important advance a smart grid has with respect to the traditional grid is that to some extent the smart grid approaches generation and storage to consumption, therefore transmission losses are reduced and problems about economic dispatch are simplified. In counterpart the necessary technology has to be mandatorily implemented, the grid redesigned and people informed previously and all of this done step by step over several years using a well-established plan for this and maintaining a continuous improvement.

The implementation of smart nano grids makes possible a better administration of a comprehensive electricity market and the main purpose of them is to provide information to the consumers and to the system to simplify the market operation and to achieve the objectives proposed based on an integrated technology bringing economic, environmental and sustainability benefits for all the parties involved.

Many schemes of electricity markets do exist as for example the one proposed in (7) which is oriented to the smart grid structure approach, and also on the other hand cases of investigations whose orientation is towards economics which is a defining aspect to consider for any future implementation ${ }^{(12)}$, or the case in which a smart mini-grid scheme is proposed as a municipal grid for grouping the nano-grids and contribute and participate into the electricity market (20). Furthermore, there are different scenarios to simulate an electricity market and at the same time the variables taken into consideration differ greatly between the investigations, as for example in the case of ${ }^{(21)}$ where an electricity market is analyzed under a genetic algorithm 
taking into consideration rated power factor, stochastic load, holding costs, short costs, startup costs and shut down costs. On the other hand, there are also models for the electricity demand uncertainty as the ones showed in (16) and (22) which contribute with the aspect of the demand response but don't take consideration of the hierarchical energy resources nor smart nanogrids.

\section{Conclusions}

Electricity markets as a whole is a general topic that involves a lot of different participants of the energy sector and their mutual interaction. Focusing the action field of the electricity market can result in a reduction or limitation of the participation of some sectors. Hierarchical energy resources is the starting point and the final purpose towards the investigation of electricity markets because its statements encompasses the real benefits for the entire society, for that reason the efforts in theory must be oriented to go in that direction fully justifying the cases in which it cannot be respected.

Electricity market is a special case in which although it is true that it is ruled by all the conceptions and constraints of every market, it has specific characteristics that must be considered and analyzed. Because of this the electricity market is a topic that teaches and requires a good effort to deal with. Smart grids, one of the latest advances in the electric area, open a huge amount of possibilities for automation, communication, consumers interaction and more, allowing the electricity market to become more flexible, reliable and supported, reaching to a world of prospects that years before could only be imagined. This knowledge and technology oriented in the way of science and reason could result in a diversity of benefits for society as a whole.

\section{References}

(1) Soares N, Martins AG, Carvalho AL, Caldeira C, Du C, Castanheira E, et al. The challenging paradigm of interrelated energy systems towards a more sustainable future. Renew Sustain Energy Rev. 2018;95:171-93. Doi: 10.1016/j.rser.2018.07.023. Avalaible from:

https://www.sciencedirect.com/science/art icle/pii/S136403211830529X.

(2) Huang B, Xie G, Kong W, Li Q. Study on smart grid and key technology system to promote the development of distributed generation. En: 2012 IEEE Innovative Smart Grid Technologies - Asia, ISGT Asia 2012 [Internet]. Tianjin, China: IEEE Institute of Electrical and Electronics Engineers; 2012. p. 1-4. Avalaible from: https://ieeexplore.ieee.org/abstract/docum ent/6303265.

(3) Garcia E, Isaac I. Demand response systems for integrating energy storage batteries for residential users. En: 2016 IEEE Ecuador Technical Chapters Meeting, ETCM 2016 [Internet]. Guayaquil, Ecuador: IEEE Institute of Electrical and Electronics Engineers; 2016. p. 1-6. Avalaible from: https://ieeexplore.ieee.org/document/7750 818.

(4) Saebi J, Javidi MH. Implementation of demand response in different control strategies of smart grids. En: 2012 2nd Iranian Conference on Smart Grids, ICSG 2012 [Internet]. Tehran, Iran: IEEE Institute of Electrical and Electronics Engineers; 2012. p. 1-4. Disponible en: https://ieeexplore.ieee.org/document/6243 525.

(5) Fahimi B, Kwasinski A, Davoudi A, Balog R, Kiani M. Charge It! IEEE Power Energy Mag [Internet]. 2011;9(4):54-64. 
Avalaible from: https://ieeexplore.ieee.org/document/5899 017.

(6) Bruno S, Giannoccaro G, La Scala M. Optimization of residential storage and energy resources under demand response schemes. En: 19th IEEE Mediterranean Eletrotechnical Conference, MELECON 2018 [Internet]. Marrakech, Morocco: IEEE Institute of Electrical and Electronics Engineers; 2018. p. 225-30. Avalaible from: https://ieeexplore.ieee.org/abstract/docum ent/8379098.

(7) Manshadi SD, Khodayar ME. A Hierarchical Electricity Market Structure for the Smart Grid Paradigm. IEEE Trans Smart Grid [Internet]. 2016;7(4):1866-75. Disponible en: https://ieeexplore.ieee.org/document/7112 538.

(8) Manoochehri H, Fereidunian A. A multimarket approach to peak-shaving in Smart Grid using time-of-use prices. En: 2016 8th International Symposium on Telecommunications, IST 2016 [Internet]. Tehran, Iran: IEEE Institute of Electrical and Electronics Engineers; 2017. p. 70712. Available from: https://ieeexplore.ieee.org/document/7881 915.

(9) Bhalshankar SS, Thorat CS. Integration of smart grid with renewable energy for energy demand management: Puducherry case study. En: International Conference on Signal Processing, Communication, Power and Embedded System, SCOPES 2016 - Proceedings [Internet]. Paralakhemundi, India: IEEE Institute of Electrical and Electronics Engineers; 2017. p. 1-5. Available from: https://ieeexplore.ieee.org/document/7955
498.

(10) Morcillo JD, Franco CJ, Angulo F. Delays in electricity market models. Energy Strateg Rev [Internet]. 2017;16:24-32. Available from: http://dx.doi.org/10.1016/j.esr.2017.02.00 4.

(11) García EM, Águila A, Isaac I, González JW, López G. Analysis of voltage profile to determine energy demand using Monte Carlo algorithms and Markov Chains (MCMC). En: 2016 51st International Universities Power Engineering Conference, UPEC [Internet]. Coimbra, Portugal: IEEE Institute of Electrical and Electronics Engineers; 2017. p. 1-6. Available from: https://ieeexplore.ieee.org/document/8114 092.

(12) De Oliveira-De Jesus PM, Antunes CH. Economic valuation of smart grid investments on electricity markets. Sustain Energy, Grids Networks [Internet]. 2018;16:70-90. Available from: https://doi.org/10.1016/j.segan.2018.05.00 3.

(13) Grimm V, Martin A, Schmidt M, Weibelzahl M, Zöttl G. Transmission and generation investment in electricity markets: The effects of market splitting and network fee regimes. Eur J Oper Res [Internet]. 2016;254(2):493-509. Available from: https://www.sciencedirect.com/science/art icle/pii/S0377221716301904.

(14) Papalexopoulos A. Lessons learned from past electricity market design models and a road map for next generation design models. En: 2006 IEEE Power Engineering Society General Meeting [Internet]. Montreal, Canada: IEEE 
Institute of Electrical and Electronics Engineers; 2008. p. 2 pp. Available from: https://ieeexplore.ieee.org/document/1709 496.

(15) Kakran S, Chanana S. Smart operations of smart grids integrated with distributed generation: A review. Renew Sustain Energy Rev [Internet]. 2018;81 part I:524-35. Available from: http://dx.doi.org/10.1016/j.rser.2017.07.04 5.

(16) Tahmasebi M, Pasupuleti J. Electricity demand uncertainty modeling using enhanced path-based scenario generation method. En: 2017 6th International Youth Conference on Energy, IYCE 2017 [Internet]. Budapest, Hungary: IEEE Institute of Electrical and Electronics Engineers; 2017. p. 1-5. Available from: https://ieeexplore.ieee.org/stamp/stamp.jsp ?arnumber $=8003747$.

(17) Ventosa M, Baíllo Á, Ramos A, Rivier M. Electricity market modeling trends. Energy Policy [Internet]. 2005;33(7):897913. Available from: https://www.sciencedirect.com/science/art icle/pii/S0301421503003161.

(18) Streimikiene D, Siksnelyte I. Sustainability assessment of electricity market models in selected developed world countries. Renew Sustain Energy Rev [Internet]. 2016;57:72-82. Available from: http://dx.doi.org/10.1016/j.rser.2015.12.11
3.

(19) Li X, Gao L, Wang G, Gao F, Wu Q. Investing and pricing with supply uncertainty in electricity market: A general view combining wholesale and retail market. China Commun [Internet]. 2015;12(3):20-34. Available from: https://ieeexplore.ieee.org/document/7084 360.

(20) Batas-Bjelic I, Rajakovic N, Duic N. Smart municipal energy grid within electricity market. Energy [Internet]. 2017;137:1277-85. Available from: https://doi.org/10.1016/j.energy.2017.06.1 77.

(21) Wu JK, Long J, Wang JX. Stochastic dynamic generation models in electricity markets. En: Conference, 2004 IEEE Industrial and Commercial Power Systems Technical [Internet]. Clearwater Beach, Florida, USA: IEEE Institute of Electrical and Electronics Engineers; 2004. p. 45-9. Available

from: https://ieeexplore.ieee.org/document/1314 980.

(22) Bina MT, Ahmadi D. Stochastic Modeling for the Next Day Domestic Demand Response Applications. IEEE Trans Power Syst [Internet]. 2015;30(6):288093. Available from: https://ieeexplore.ieee.org/document/7010 039.

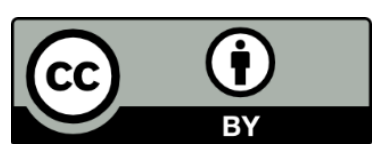

Revista Ingeniería y Competitividad por Universidad del Valle se encuentra bajo una licencia Creative Commons Reconocimiento - Debe reconocer adecuadamente la autoría, proporcionar un enlace a la licencia e indicar si se han realizado cambios. Puede hacerlo de cualquier manera razonable, pero no de una manera que sugiera que tiene el apoyo del licenciador o lo recibe por el uso que hace. 